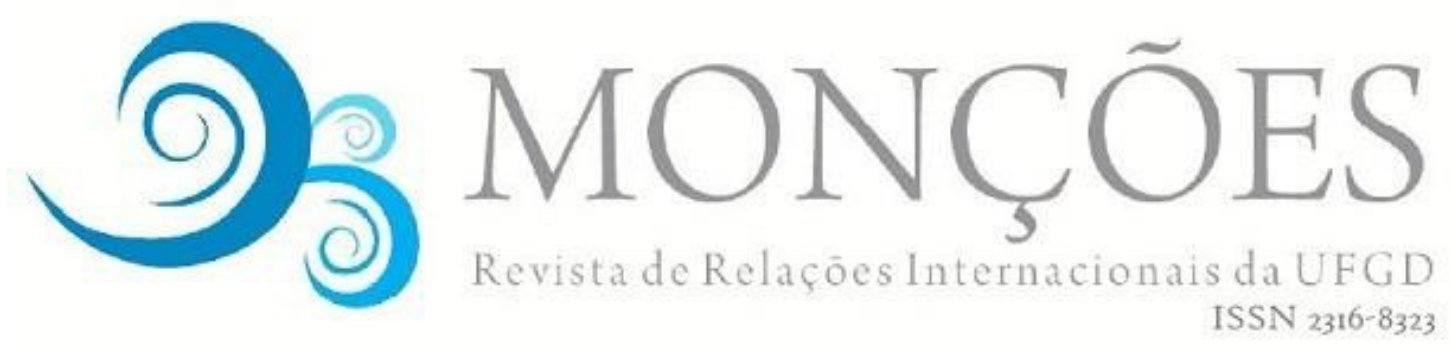

\title{
MULHERES EM REFÚGIO: A MARGINALIZAÇÃO DE REFUGIADAS EM UM SISTEMA INTERNACIONAL HIERARQUIZADO
}

\author{
Rafaela Julich Morais \\ Mestre em Relações Internacionais pela UFSC \\ Agente de Integração de Pessoas Refugiadas na Círculos de Hospitalidade \\ rafaelajulich@hotmail.com
}

Resumo: O principal objetivo deste artigo é analisar como as mulheres refugiadas do Sul Global são tratadas pelo Sistema Internacional e pelo Regime Internacional de Refúgio. A hipótese do trabalho parte do nível sistêmico e conclui que as mulheres refugiadas são excluídas política, social e economicamente de ambas as esferas e tal exclusão é refletida também nas sociedades de acolhida. Essa marginalização ocorre devido às relações coloniais de poder que moldam o globo em múltiplas hierarquias de gênero, raça, etnia, nacionalidade e status migratório, as quais inferiorizam as mulheres que buscam por refúgio tanto no próprio Sul quanto no Norte Global. Fez-se uma revisão bibliográfica sobre a edificação hierárquica e dicotômica do Sistema Internacional com base na exploração e inferiorização do Sul Global; sobre as contradições do Regime Internacional de Refúgio e a construção de "mitos da diferença" que retrataram e continuam a representar pessoas refugiadas como "ameaças" à segurança e à cultura nacionais; sobre a categorização das mulheres em situação de refúgio como vulneráveis, e; por fim, sobre a necessidade de se incorporar um olhar interseccional às análises de processos migratórios forçados.

Palavras-chave: Sistema Internacional. Colonialidade do Poder. Mulheres Refugiadas.

\section{WOMEN IN REFUGE: THE MARGINALIZATION OF REFUGEE WOMEN IN A HIERARCHIZED INTERNATIONAL SYSTEM}

\begin{abstract}
The main objective of this article is to analyze how refugee women from the Global South are treated by the International System and the International Refugee Regime. The hypothesis starts at the systemic level and concludes that refugee women are excluded politically, socially and economically from both spheres and this exclusion is also reflected in host societies. This marginalization occurs due to the colonial power relations that shape the globe in multiple hierarchies of gender, race, ethnicity, nationality and migratory status, which categorize women who seek refuge in the South as well as in the Global North as inferior beings. The article made a bibliographic review on the hierarchical and dichotomous construction of the International System based on the exploitation and inferiorization of the Global South; on the contradictions of the International Refugee Regime and the construction of "myths of difference" that portrayed and continue to represent refugee people as "threats" to national security and culture; on the categorization of women on the move as vulnerable, and; finally, on the need to incorporate an intersectional lense into the analysis of forced migration processes.
\end{abstract}

Keywords: International System. Coloniality of Power. Refugee Women. 


\section{INTRODUÇÃO}

Para o universo teórico tradicional das Relações Internacionais (RI), o estudo do poder tem sido central para a organização e produção do conhecimento dentro da disciplina. Tradicionalmente, as RI lidam em grande medida com as políticas das grandes potências e assuntos relacionados à segurança estatal. À vista disso, as assimetrias globais de poder no âmbito político, econômico e social são muitas vezes negligenciadas pelas teorias mainstream. Naturaliza-se assim as hierarquias de raça, etnia, gênero e classe no mundo e se reproduz o status quo nas principais linhas de pensamento da área.

Como Greta Chowdbry e Sheila Nair (2002) argumentam, para que as Relações Internacionais sejam verdadeiramente internacionais é preciso reconhecer a forma como a interação destas questões (de raça, de etnia, de gênero, de classe versus o poder) trabalha na construção das dissimetrias do mundo globalizado. Surgem, então, obras críticas que mudaram a orientação da produção do conhecimento em RI: são consideradas as diferentes configurações e efeitos da Política Internacional, que ao fim e ao cabo articulam as desigualdades de poder entre os Estados e as populações (CHOWDBRY; NAIR, 2002).

Nesse sentido, a temática das migrações internacionais, particularmente das migrações forçadas, tem penetrado cada vez mais as agendas de pesquisa e discussões das RI. Isto pois as causas, consequências e respostas dadas aos fluxos migratórios envolvem variáveis substanciais da Política Internacional e das discrepâncias de poder no Sistema Internacional, entre elas: os envolvimentos e interesses hegemônicos em conflitos internos no Sul Global; as desigualdades socioeconômicas entre países; a securitização das migrações; o racismo estrutural, e; as hierarquias dissimétricas de gênero do Sistema Internacional.

O tema das migrações internacionais forçadas não é recente, uma vez que a noção de asilo ou proteção dada a estrangeiros por outro Estado tem sido discutida pelos Estados há séculos (HADDAD, 2008). Todavia, a escala do deslocamento forçado mundial atualmente é nova quando analisados seus números brutos: conforme o relatório anual "Tendências Globais" do Alto Comissariado das Nações 
Unidas para Refugiados (ACNUR), 70,8 milhões de pessoas foram forçadas a se deslocar por fronteiras nacionais e transnacionais até o fim de 2018 (ACNUR, 2019).

Como apontado pelas Tendências Globais do ACNUR (2019), nota-se em 2018 a continuidade de múltiplas "crises"11 de deslocamento forçado, porém o ano também foi caracterizado por diversas novas tendências migratórias. Uma renovada onda migratória foi observada na República Democrática do Congo que, devido à intensificação e expansão do conflito civil em novas áreas do país, forçou mais de 5 milhões de indivíduos a migrar (ACNUR, 2019). A instabilidade econômica e política na Venezuela também gerou acentuados movimentos de pessoas para regiões diversas da América Latina, totalizando 3,4 milhões de refugiadas(os) e solicitantes de refúgio no fim de 2018 (ACNUR, 2019).

No intuito de se alcançar o objetivo aqui proposto de compreender a exclusão das refugiadas do $\mathrm{SI}$, os métodos de análises e procedimentos empregados pela pesquisa serão qualitativos, sendo feita uma revisão bibliográfica do Sistema Internacional e do Regime Internacional ${ }^{2}$ de Refúgio a partir de perspectivas teóricas críticas, em especial as pós-coloniais e decoloniais.

Foram utilizadas principalmente fontes secundárias, como dissertações, teses, livros acadêmicos e artigos científicos sobre o tema. O material foi coletado de Bibliotecas Universitárias e de sites acadêmicos eletrônicos. Ademais, fontes secundárias pesquisadas em jornais e noticiários eletrônicos como o The Guardian, a $\mathrm{BBC}$, o G1, entre outros, também foram utilizadas.

\footnotetext{
${ }^{1}$ Fazendo uma análise dos resultados de pesquisa na ferramenta Google, organizações como o ACNUR, a OXFAM, a International Rescue Comittee e a CARE, além de jornais virtuais como a BBC, o Aljazeera, o The Economist, a Reuters, entre outros, todas utilizam o termo "crise" para referenciar o intenso fluxo migratório atual de pessoas deslocadas por conflitos e perseguições diversas. Aqui, prefere-se utilizar o termo em aspas de forma crítica, visto que seu uso denota uma culpabilidade dos indivíduos que estão em movimento. Na realidade, esses intensos fluxos atuais são causados por uma gama diversa de fatores, entre eles as intervenções militares ocidentais nos países do Sul. Ademais, a utilização do termo "crise" está relacionada ao tratamento repressivo destes refugiados e com a edificação de fronteiras virtuais e físicas.

2 Prefere-se aqui utilizar a definição construtivista de regime em contraste à realista de Stephen Krasner (2012), para a qual regimes são "princípios, normas e regras implícitos ou explícitos e procedimentos de tomada de decisões de determinada área das relações internacionais em torno dos quais convergem as expectativas dos atores". Para o termo "regime", utiliza-se nesse trabalho a definição construtivista de Kratochwil e Ruggie (1986). $\mathrm{Na}$ visão construtivista, os regimes surgem a partir de arranjos governamentais construídos pelos Estados para coordenar suas expectativas e organizar em diversos aspectos e áreas o comportamento internacional. Regimes, portanto, compreendem elementos normativos, práticas estatais e papeis organizacionais (KRATOCHWIL; RUGGIE, 1986). A escolha por usar a definição construtivista dá-se pela limitação da realista, em especial as precisões conceituais quanto as hierarquias entre os membros de um regime, além da pouca consideração às interpretações e compreensões subjetivas dos atores envolvidos. Assim, considera-se o regimento dos fluxos migratórios no que diz respeito o refúgio internacional - ou seja, a Convenção de Genebra para Refugiados de 1951 e seu subsequente Protocolo de 1967 - um regime nos moldes construtivistas: o Regime Internacional de Refúgio foi estabelecido com o propósito de coordenar e organizar o comportamento dos Estados na temática da proteção de indivíduos que sofrem perseguições diversas.
} 
Sobre o estado da arte escrito acerca do tema do refúgio a nível sistêmico, destacam-se as pesquisas de Chimni (1998), Bhambra (2015), Grosfoguel (2017), Scalettaris (2007) e Haddad (2008) acerca da hierarquia racial/cultural do regime internacional. Para uma perspectiva mais ampla da colonialidade do Sistema Internacional, foi-se revisados estudos decoloniais como os de Grosfoguel (2008), Chowdbry e Nair (2002), Doty (1996), Quijano (2000), Grovogui (2013), entre outros e outras. Acerca da questão de gênero no âmbito do refúgio, as pesquisas de Freedman (2007), Fiddian-Qasmiyeh (2014) e Bartolomei e Pittaway (2001) mostraram-se imprescindíveis para o exame das maneiras como os marcadores de gênero influenciam tanto nas razões pelas quais mulheres são obrigadas a se deslocar, como suas experiências nas rotas migratórias. Além disso, reconhecendo a importância de se considerar os efeitos da interseccionalidade de gênero, raça, etnia e status migratório no deslocamento de mulheres, foram revisadas obras de autoras como Crenshaw (1989), Collins (2000) e Lugones (2014).

Ao expor aqui a exclusão social, econômica e política de mulheres refugiadas no Sistema Internacional, buscou-se tomar o cuidado metodológico de não promover generalizações das refugiadas como um grupo homogêneo e monolítico. Reconhecese a diversidade étnica, racial, cultural entre as mulheres que buscam refúgio, e destaca-se também o lugar de fala distinto da pesquisadora no que tange possíveis diferenças de raça, etnia, status migratório e posição geográfica. Não é intenção do trabalho "falar pelas" mulheres em situação de refúgio, mas dar visibilidade às questões hierárquicas de gênero, raça, etnia e status migratório que comumente são ignoradas na área das Relações Internacionais.

\section{RELAÇÕES COLONIAIS DE PODER: AS HIERARQUIAS HISTÓRICAS DO SISTEMA INTERNACIONAL E SEUS IMPACTOS NOS DESLOCAMENTOS FORÇADOS}

Quando se compreende no seu aspecto imediato o contexto colonial, é evidente que o que divide o mundo é sobretudo o fato de se pertencer ou não a tal espécie, a tal raça.

(FANON, 1961, p. 35)

Como aponta Lisa Malkki (1995), o contexto dos deslocamentos humanos envolve temas e práticas que fazem parte de uma enorme constelação sociopolítica e 
cultural, por vezes dicotômicas: questões como o nacionalismo e o racismo, a xenofobia e as políticas migratórias, as práticas violentas de um Estado e a guerra, a censura e o silenciamento, os direitos humanos e os desafios à soberania estatal, os discursos desenvolvimentistas e as intervenções humanitárias, a cidadania e as identidades religiosas e culturais (MALKKI, 1995). Por conseguinte, a temática das migrações forçadas oferece um arranjo diversificado de assuntos que podem ser explorados academicamente, em especial no domínio teórico e metodológico das Relações Internacionais.

De acordo com Alexander Betts (2014), as causas, consequências e respostas aos fluxos migratórios estão intimamente relacionadas à Política Internacional, pois envolvem problemáticas características do universo das RI. As causas dos movimentos de pessoas em situação de refúgio estão enraizadas em conflitos intra e interestatais e na falha dos Estados em proteger os direitos básicos dos cidadãos. Também podem estar relacionadas às desigualdades da Política Econômica Internacional (BETTS, 2014). As consequências destes movimentos, ainda conforme Betts (2014), são tradicionalmente atreladas à segurança internacional, ao terrorismo e transnacionalismo. Por outro lado, as respostas dadas aos fluxos de deslocamento são em geral associadas aos desafios à cooperação internacional e aos papéis das instituições internacionais e do Direito Internacional (BETTS, 2014).

É preciso, todavia, problematizar estas análises tradicionais, sobretudo as abordagens que tendem a securitizar o refúgio ou aquelas que consideram a intensificação dos fluxos migratórios forçados como um "problema do Terceiro Mundo" (MALKKI, 1995, p. 503). Isto pois os movimentos de refugiados estão visceralmente conectados aos desequilíbrios e desigualdades de poder no cenário internacional, os quais remetem à própria constituição do SI e, posteriormente, do Regime de Refúgio.

Dentro o universo epistemológico tradicional das Relações Internacionais, o estudo do poder tem sido central para a organização e produção do conhecimento dentro da disciplina. Tradicionalmente, as RI lidam em grande medida com as políticas das grandes potências e assuntos relacionados à segurança estatal, privilegiando o Estado como ator central. Em vista disso, as assimetrias de poder no âmbito político, econômico e social são muitas vezes negligenciadas nas teorias mainstream. Naturaliza-se, por conseguinte, as hierarquias de raça, etnia, gênero e classe, e 
reproduz-se o status quo nas principais linhas de pensamento da disciplina (CHOWDBRY; NAIR, 2002).

Para que seja possível a análise do SI e do RIR, é necessário, em primeiro lugar, compreender os impactos da divisão do mundo em dicotomias hierárquicas intrínsecas à política mundial. A importância dessa análise para a pergunta proposta pelo artigo dá-se pelo modo como as assimetrias de poder entre Estados datadas desde a exploração colonial irão construir uma imagem inferiorizada da mulher, da pessoa racialmente identificada e da(o) estrangeira(o) situadas(os) no Sul.

Nas teorias mainstream, o SI é dado como um sistema de Estados formado por duas ou mais unidades com suficiente contato e impacto em suas relações e processos decisórios, a tal ponto que seus comportamentos e ações torna-os parte de um todo (BULL, 2001). O Sistema Internacional que alicerça as RI, desse modo, essencialmente teria tomado forma com o estabelecimento do sistema de Estados westfalianos no século XVII.

Contudo, como argumentado por estudiosos de correntes decoloniais e póscoloniais, tanto as RI quanto o SI foram concebidos a partir do encontro entre Europa, Américas, Áfricas e Ásias, ou seja, através da expansão colonial no século XV (GROVOGUI, 2013; CHOWDBRY; NAIR, 2002; DOTY, 1996; GROSFOGUEL, 2008; QUIJANO, 2000; FANON, 1961). Como Giba Grovogui (2013, p. 251) salienta, seria equivocado abraçarmos cegamente categorias como a "ordem internacional", "sociedade internacional", a "ética internacional" e o próprio Sistema sem um profundo exame destes conceitos, posto que remetem à expansão imperial europeia na era colonial e não são desprovidos de efeitos políticos.

Frantz Fanon (1961, p. 35) aponta que a partir deste encontro o mundo foi (e continua sendo) dividido em dois, "habitado por espécies diferentes": os colonizadores e os colonizados ou, contextualizando a partir do cenário atual, entre Norte e Sul Globais. A partir da ocupação e colonização de outras regiões, assinala Grovogui (2013, p. 247), a "auto-identificada Europa" passou a gerir o mundo conquistado a partir de sua própria imagem. De fato, a grande maioria das pesquisas pós-coloniais e decoloniais parte da premissa de que as identidades nacionais do mundo colonizado são estabelecidas em oposição às europeias/ocidentais, construindo então o que viriam a ser os "outros" (CHOWDBRY; NAIR, 2002, p. 2; SAID, 1990, p. 13). Geeta Chowdbry e Sheila Nair (2002) ainda destacam a importância de se considerar não 
somente os impactos das práticas coloniais na produção e reprodução de identidades, como também a relevância das questões de raça, classe e gênero para o discernimento dos processos de dominação e resistência.

Em termos realistas, Kenneth Waltz (1979, p. 93) aponta que as conjunturas e a distribuição de capacidades dentro do Sistema Internacional "são definidas não por todos os atores [...], mas pelos atores poderosos", dentro de uma estrutura anárquica. Em contrapartida, como argumentam Chowdbry e Nair (2002), é a condição hierárquica e não anárquica que privilegia uns atores e não outros no âmbito do SI. Waltz (1979) não questiona a distribuição de capacidades - ou poderes - entre os atores mais fortes do Sistema, ou como esta distribuição deu-se através da colonização e exploração sistemática do Sul Global (CHOWDBRY; NAIR, 2002).

Não obstante, o SI foi arquitetado através da formação de classes sociais dissimétricas em escala global (GROSFOGUEL, 2008), da divisão internacional do trabalho entre centro, semiperiferia e periferias (WALLERSTEIN, 1974), da criação de uma hierarquia étnico-racial onde os povos brancos europeus foram privilegiados em relação aos não-europeus (QUIJANO, 2000) e os homens em relação às mulheres (SPIVAK, 1988).

De acordo com Ramón Grosfoguel (2008), a divisão colonial do Sistema Internacional, portanto, acarretou uma:

\footnotetext{
Interseccionalidade de múltiplas e heterogêneas hierarquias globais de formas de dominação e exploração sexual, política, epistêmica, econômica, espiritual, linguística e racial, em que a hierarquia étnico-racial do fosso cavado entre o europeu e o não-europeu reconfigura transversalmente todas as restantes estruturas globais de poder.

(GROSFOGUEL, 2008, p. 7)
}

Argumenta-se no presente trabalho que a mencionada hierarquia étnico-racial que arquitetou o Sistema Internacional acarreta a atual marginalização prática e epistemológica de mulheres refugiadas tanto de discussões políticas e acadêmicas quanto da vida social e econômica das sociedades que as acolhem. Aliás, essa hierarquia também está presente na experiência de mulheres que se refugiam em países como o Brasil, ainda que este seja semiperiférico e não-europeu. Essa exclusão é aprofundada a nível internacional e local quando aplicamos ao estudo a lente interseccional e observamos a confluência de diversos marcadores que intensificam as opressões sofridas pelas mulheres em situação de refúgio. 
Diante dessa breve contextualização acerca das assimetrias enraizadas nas RI e no SI, a próxima subseção tem como objetivo revisar criticamente e mais profundamente os impactos da criação ocidental da "nação, das questões de raça e do jogo de interesses políticos dominantes na contínua marginalização de migrantes do Sul Global.

\section{MITOS DA "DIFERENÇA": A ESTRUTURAÇÃO DO SISTEMA INTERNACIONAL E A EXCLUSÃO DAS(OS) REFUGIADAS(OS) DO SUL}

Apesar de muito ser escrito e estudado acerca das preocupações domésticas que as pessoas em situação de refúgio podem vir a acarretar, o possível "peso" às economias nacionais ou a ameaça às identidades nacionais, as(os) refugiadas(os) representam as falhas do Sistema Internacional moderno baseado no Estado-nação (HADDAD, 2008, p. 15). As pessoas forçadas a se deslocar são a intersecção entre o internacional e o doméstico, visto como desafiam não apenas questões de pertencimento e identidade, mas também distinções disciplinarias em um Sistema moldado em dicotomias (HADDAD, 2008). De fato, o tema do refúgio traz à tona o embate entre diversos conceitos tradicionais das Relações Internacionais: o pluralismo e o solidarismo, o comunitarismo e o cosmopolitanismo, os direitos de soberania e os direitos humanos (HADDAD, 2008).

No que tange o tema do refúgio nas $\mathrm{RI}$, parece difícil desassociar os temas que envolvem a soberania e as fronteiras estatais, pois estas baseiam todo o Sistema Internacional. A soberania é respaldada pela nacionalização do Estado, que somente foi possível através da construção da identidade do cidadão (HADDAD, 2008). Posto que toda sociedade deve ter um local onde residir, existe uma conexão entre o Estado, a nação e o território que vem a dominar a construção do Sistema. Ainda, ao passo que toda sociedade necessita de um território, fora dele as pessoas podem representar uma ameaça à sua estabilidade.

Como apontado por Fiona Adamson (2006), o fim da Guerra Fria transformou a natureza e a função das fronteiras nacionais, de forma que vemos uma maior securitização das migrações e um aumento do policiamento das fronteiras. O que parece ocorrer é a crescente preocupação com a segurança devido aos fluxos de pessoas deslocadas. Entretanto, a autora aponta que os Estados tradicionalmente 
forjam suas políticas nacionais de migração em resposta aos seus interesses econômicos e de segurança, sendo que através das políticas os migrantes muitas vezes são apontados como ameaças, em especial durante tempos de crise política e econômica (ADAMSON, 2006). Desta forma, é possível notar uma ligação direta entre as políticas migratórias e o racismo e a xenofobia. Ao enfatizar a necessidade de restrições e do controle de fronteiras, implica-se uma imagem negativa aos grupos de migrantes e sustentam-se expressões públicas de racismo e xenofobia dentro do contexto político.

Consequentemente, além da criação da diferença entre o cidadão e o estrangeiro, o processo de construção do Estado-nação envolveu o desenvolvimento da representação da migração como um perigo, onde o significado cultural do controle de fronteiras mostra-se um elemento central (HUYSMANS, 2000). Apontado como um problema interno de segurança, o controle das fronteiras possui uma dimensão cultural, e os indivíduos cruzando fronteiras são frequentemente diferenciados de acordo com diversos critérios. Visto como a maioria das(os) solicitantes de refúgio vem de países do Sul Global, elas(es) são caracterizadas(os) como cultural e racialmente diferentes (HUYSMANS, 2000), ou seja, observa-se a diferenciação do "outro".

Conforme Haddad (2008), isto ocorre pois a definição clara da soberania dos Estados cria uma dicotomia de exclusão que pode ser em termos de espaço (dentro versus fora), de membresia a uma comunidade específica (cidadão versus nãocidadão) e agência (Estado versus indivíduo, ou seja, os direitos e deveres de um perante o outro e vice-versa). Por consequência, a criação da identidade da(o) estrangeira(o) foi vital para o estabelecimento da hierarquia "Estado-cidadão-território" (HADDAD, 2008, p. 67). A cidadania, como argumenta Grosfoguel (2017), foi desde seu início um mecanismo essencial para a edificação das fronteiras que dividem os centros das periferias no Sistema Internacional, marginalizando mulheres, classes trabalhadoras e populações não-ocidentais ao acesso dos privilégios, recursos e direitos humanos no Norte Global.

Percebe-se que para a formação do SI foi essencial a criação do "outro", isto é, de indivíduos que pertencessem a outro território nacional para que se criassem e reafirmassem suas próprias identidades (HADDAD, 2008; SAID, 1998; GROSFOGUEL, 2017). Esses processos de alterização ocorreram de forma a 
consolidar a dominação imperial europeia, através de métodos de discriminação prática e cultural aplicados às sociedades não-ocidentais (SAID, 1990).

Além da soberania, o tema da raça é igualmente imprescindível para a compreensão da questão do refúgio. A raça tem sido por muito tempo ignorada na disciplina de Relações Internacionais, pois, de acordo com Randolph Persaud (2002), o tema da raça é visto como uma categoria morfológica, enquanto as RI concernem principalmente com questões estratégicas.

Entretanto, análises que levam em consideração o marcador da raça têm ampliado cada vez mais o escopo para incluir questões relacionados ao gênero, identidade, cultura, etnia, classe e até mesmo questões que envolvem o nacionalismo (PERSAUD, 2002). O que se percebe é que a raça, o gênero e a classe não são sistemas desassociados, mas sim processos históricos interconectados e que afetam as Relações Internacionais.

A raça como um instrumento de poder é, conforme Aníbal Quijano (2005, p. 117), "uma construção mental que expressa a experiência básica da dominação colonial e que desde então permeia as dimensões mais importantes do poder mundial". Assim, as noções de raça e cultura vão trabalhar como categorizações que geram identidades antagônicas e vão justificar o exercício do poder por parte dos países ocidentais (CASTRO-GOMEZ; GROSFOGUEL, 2005).

A criação do "outro" na imagem das(os) refugiadas(os) dá-se no contexto da hierarquia étnico-racial do SI, que implicou uma "formação racial/colonial global" de significados, discursos e estruturas em torno da hierarquia de raça (GROSFOGUEL, 2017, p. 227). Por muito tempo, o racismo biológico foi o discurso dominante; após a Segunda Guerra Mundial, no entanto, observamos a mudança do discurso global para a formação de racismos predominantemente culturais (GROSFOGUEL, 2017).

No entanto, como aponta Grosfoguel (2017, p. 228), o "racismo cultural" está sempre relacionado a uma noção de "racismo biológico", posto que a cultura é naturalizada em termos de uma noção hierárquica entre culturas superiores e inferiores, associadas aos corpos biológicos dos indivíduos. Ainda:

O racismo cultural é sempre articulado em relação aos discursos da pobreza, das oportunidades nos mercados de trabalho e da marginalização. $O$ problema da pobreza ou do desemprego das minorias racializadas é construído como um problema de hábitos ou crenças, isto é, como um "problema cultural", assumindo inferioridade cultural e, portanto, naturalizando/fixando/essencializando a cultura do "Outro". 
(GROSFOGUEL, 2017, p. 228)

Tanto é verdade que no período entreguerras, quando a(o) refugiada(o) era a pessoa europeia que se deslocava dentro do próprio continente, B.S. Chimni (1998) aponta que as políticas tendiam a ter um caráter de abertura e acolhimento. Criou-se, assim, a imagem do refugiado "normal", que era "branco, do sexo masculino e anticomunista" (CHIMNI, 1998, p. 357).

Essa imagem passou a ser justaposta bruscamente pela figura da(o) "nova(o)" migrante que foge do hemisfério Sul, em especial a partir dos processos de descolonização da África ao longo do século XX (CHIMNI, 1998, p. 357). Com a transformação da identidade do refugiado europeu para aquela(e) que fugia do Sul devido a conflitos muitas vezes incitados por iniciativas ocidentais, as políticas do Norte passam a ter traços de contenção (CHIMNI, 1998).

Com o fim das tensões entre Estados Unidos e União Soviética e a consequente vitória das nações Ocidentais sobre o comunismo, Chimni (1998) demonstra que as razões ideológicas para a aceitação de refugiada(os) mudaram tanto nos Estados Unidos quanto na Europa. Com o fim da Guerra Fria e a chegada das(os) "novas(os) solicitantes de refúgio" vindas(os) do Sul Global, houve um processo de transformação das políticas migratórias. Esta renovação do pensamento traduziu-se em uma série de medidas restritivas, ao passo que as pessoas em situação de refúgio perderam seu valor ideológico e político (CHIMNI, 1998, p. 351).

Neste contexto, as(os) refugiadas(os) não mais representavam um símbolo político que poderia ser utilizado para "ganhar pontos em relação ao adversário", mas são vistas(os) como uma ameaça a ser contida (CHIMNI, 1998, p. 351). A(o) refugiada(o) da Somália, do Iraque ou da República Democrática do Congo que bate às portas da Europa ou da América do Norte não simboliza a superioridade do bloco capitalista diante daqueles que fugiam da União Soviética nas décadas de 1960 e 1970; agora, elas(es) são tratadas(os) como as próprias causas das "crises" migratórias (FREEDMAN, 2007, p. 11).

As crescentes desigualdades entre Estados ricos e pobres que se intensificaram no período pós-Guerra Fria contribuem para a inflamação das crises no Sul Global, as quais estão intimamente relacionadas às causas da migração forçada (FREEDMAN, 2007). As relações de poder desiguais, aponta Freedman (2007), 
também foram amplificadas pela mudança no padrão da ajuda externa por parte dos países ocidentais, com um declínio da assistência de longo prazo para o desenvolvimento e o aumento do financiamento para emergências humanitárias.

As mudanças de paradigmas na política internacional do refúgio coincidiram com a criação do mito da diferença: os fluxos de pessoas deslocadas vindas do Sul passaram a ser caracterizados como radicalmente diferentes dos fluxos na Europa desde o fim da Segunda Guerra Mundial (CHIMNI, 1998). De acordo com Chimni (1998) alguns fatores embasaram o argumento ocidental de que os "novos" fluxos de refugiada(os) representavam uma ruptura com os do passado: em primeiro lugar, em termos quantitativos, as crises pós-1960 possuíam uma magnitude sem precedentes. É interessante notar que esta mudança na magnitude das "crises" estava intimamente relacionada ao processo de descolonização de África (CHIMNI, 1998).

Outro mito da diferença criado pelo Ocidente e apontado por Chimni (1998) está relacionado à característica individual das pessoas refugiadas europeias se comparadas a(os) "novas(os)" refugiadas(os) do Sul: as primeiras atenderiam ao critério do deslocamento devido à perseguição política, enquanto as últimas representariam um movimento disfarçado de migração econômica, e não política.

Este ponto está intimamente conectado ao terceiro mito da diferença: o de que, ao contrário dos refugiados europeus, os indivíduos se deslocavam do Sul por conflitos internos, portanto o Estado pós-colonial deveria ser responsabilizado (CHIMNI, 1998). Com a criação destes mitos e o reforço da imagem da(o) refugiada(o) "normal", fundado em características europeias, uma clara e falsa mensagem estava e continua sendo enviada aos Estados receptores de refugiadas(os): que a quantidade de migrantes é exacerbada, que estes chegam ao país sem uma razão pertinente e abusam de suas hospitalidades (CHIMNI, 1998).

No contexto dos mitos da diferença, é importante considerar que os processos de inclusão e exclusão no mundo globalizado afetam profundamente a forma como as populações de países ocidentais interagem com aquelas do Sul. O suposto "medo" do Ocidente da migração "desgovernada" prepondera nesta relação e, por consequência, observa-se a elevação e fortificação de fronteiras (FREEDMAN, 2007, p. 10), tanto físicas quanto imaginárias. Estes mesmos processos de inclusão e exclusão marcam a reestruturação dos limites da migração, ao passo que o Norte se torna cada vez 
mais livre para se movimentar através do globo e o Sul encontra novas barreiras em seu deslocamento (CASTLES, 2003).

Através de políticas migratórias restritivas que criminalizam e marginalizam as(os) refugiadas(os) nas sociedades receptoras, observamos na prática o empreendimento do "racismo cultural" contra essas populações. A categorização hierárquica que divide culturas entre inferiores e superiores, geralmente articulada aos discursos de pobreza e de oportunidades nos mercados de trabalho (GROSFOGUEL, 2017), estereotipa a pessoa refugiada como aquela que advém de uma cultura atrasada, que solicita refúgio para usufruir das vantagens econômicas do Estado receptor e que irá de alguma forma "contaminar" a cultura ocidental ${ }^{3}$.

Observa-se esse tipo de discurso não apenas nos países do Norte Global, mas também no hemisfério Sul, onde estão localizados mais de $85 \%$ das populações refugiadas em todo o mundo 4 . Em primeiro lugar, essa porcentagem desconstrói um dos principais mitos da diferença criados pelo Ocidente para categorizar as(os) "novas(os)" refugiadas(os): de que o número de migrantes chegando no Ocidente seria excessivo.

Em segundo lugar, o expressivo número de pessoas que se refugiam dentro do Sul Global exige que analisemos o modo como essas(es) refugiadas(os) são integradas(os) e protegidas(os) nesta região. Em 2015, por exemplo, aumentaram em $633 \%$ as denúncias de xenofobia contra migrantes no Brasil (HUFFPOST BRASIL, 2016). Não apenas o aumento das denúncias contra a xenofobia explicita a hierarquização de poder, gênero e raça que excluem populações migrantes, mas também como a intensificação dos fluxos migratórios é percebida pela sociedade local e representada nos principais meios midiáticos. No contexto brasileiro, o aumento na entrada de pessoas em situação de refúgio advindas da Venezuela é muitas vezes

\footnotetext{
${ }^{3}$ Em pesquisa realizada pelo European Network Against Racism (ENAR) no contexto do aumento das solicitações de refúgio na Europa em 2015-2016, discursos racistas e com teor anti-imigrantista de políticos e ramos midiáticos mostram ser uma das principais causas do aumento da xenofobia e discriminação contra migrantes em necessidade de proteção humanitária. A introdução de políticas de restrição de fronteiras e o discurso que relaciona o refúgio ao terrorismo têm levado ao policiamento discriminatório de imigrantes, além de ataques contra requerentes de refúgio e refugiadas. Ademais, observa-se o racismo cultural na prática, ao passo que a pesquisa mostra que as iniciativas de integração em alguns países da União Europeia impõem a ideia de que o migrante deveria, em primeiro lugar, se adaptar aos "valores ocidentais", remetendo a uma suposta superioridade cultural. Disponível em: <https://ec.europa.eu/migrant-integration/librarydoc/racism-and-discrimination-in-the-context-ofmigration-in-europe-1> Acesso em: 23/08/2018.

${ }^{4}$ De acordo com os dados publicados pelo ACNUR (2018), no relatório anual Tendências Globais.
} 
apontado como uma "crise migratória" que tende a intensificar os problemas sociais locais 5 .

Essa representação, por sua vez, marginaliza ainda mais a situação social e econômica desses indivíduos, em especial das mulheres. É preciso, por fim, como as hierarquizações de poder e suas interseções (quanto ao gênero, a raça e a classe) são manifestações locais de processos transnacionais da colonialidade, da modernidade eurocêntrica e da globalização neoliberal.

Para dar continuidade ao entendimento das razões pelas quais as mulheres refugiadas são excluídas do Sistema e do Regime de Refúgio Internacionais, a próxima seção tem como objetivo revisar criticamente as denotações atreladas a quem é (e quem não é) uma pessoa refugiada e as dificuldades inerentes de um conceito enraizado em desigualdades colonizadas.

\section{O REGIME INTERNACIONAL DE REFÚGIO: QUESTÕES DE CATEGORIZAÇÃO E CONSEQUENTE MARGINALIZAÇÃO}

Como nomear um conceito que desafia a definição, uma vez que é impossível fazer generalizações sobre a vasta gama de eventos horríveis que forçam indivíduos a se tornarem refugiados? Além disso, em um campo ligado aos seres humanos e ao sofrimento humano, como podemos evitar que a refugiada seja simplesmente um instrumento de investigação acadêmica e, em vez disso, garantir que o processo de definição atenda à própria refugiada?

(HADDAD, 2008, p. 24)

Para Emma Haddad (2008, p. 24), a temática do refúgio é, em primeira instância, uma problemática de categorização. A categorização de conceitos é um mecanismo descritivo, normativo, mas sobretudo político, e por isso não se inicia uma discussão sobre o tema do deslocamento forçado sem antes ter a noção exata do que é - e do que não é - o objeto de análise (HADDAD, 2008). Assim, utilizar o termo "refugiada(o)" é tanto um ato descritivo quanto normativo, visto que ele descreve e atribui valor aos indivíduos (HADDAD, 2008, p. 24).

\footnotetext{
${ }^{5}$ Por exemplo, a reportagem do Jornal Hoje em agosto de 2017 retrata a entrada de migrantes venezuelanas(os) em Roraima como responsável por situar o Brasil no "drama dos refugiados". Disponível em: <https://globoplay.globo.com/v/6077077/> Acesso em: 26/08/2018. Outra reportagem, do Domingo Espetacular em fevereiro de 2018, argumenta que "os imigrantes chegam em municípios que já enfrentam problemas sociais e a realidade só piora. Em cidades como Pacaraima, em Roraima, e a capital Boa Vista, a criminalidade aumentou, assim como o desemprego e a prostituição." Disponível em: <https://noticias.r7.com/domingoespetacular/videos/migracao-em-massa-de-venezuelanos-muda-a-realidade-do-lado-brasileiro-da-fronteira21022018> Acesso em: 26/08/2018.
} 
Giulia Scalettaris (2007, p. 40) aponta que ser uma pessoa "refugiada" não é necessariamente uma característica natural, nem uma condição que afeta profundamente a identidade ou comportamentos e estratégias coletivos. Estar em situação de refúgio significa, primordialmente, ter um status oficial específico que é atribuído e reconhecido por instituições governamentais e internacionais. De fato, o que concretamente separa as(o)s refugiadas(os) de outros migrantes é o fato de serem rotuladas como diferentes (SCALETTARIS, 2007).

A partir da Convenção de Genebra de 1951, a pessoa refugiada foi categorizada como aquela(e) que "está fora de seu país de origem devido a fundados temores de perseguição relacionados a questões de raça, religião, nacionalidade, pertencimento a um determinado grupo social ou opinião política" (CONVENÇÃO DE GENEBRA, 1951).

$\mathrm{Na}$ época, tal definição aplicava-se apenas a pessoas individuais e possuía uma grave limitação temporal e geográfica (DAVIES, 2002). Essa definição individualista e limitada não foi obra acidental: estudos sobre a edificação do RIR demonstram como este foi desenhado a partir de interesses e preocupações dos Estados ocidentais (DAVIES, 2002; BETTS; LOESCHER, 2010). Quando se leva em consideração o contexto da Guerra Fria, a motivação em manter um conceito estreito que aplicasse a pessoas específicas era conveniente, pois histórias individuais de perseguição destacavam a situação de Estados em que o Ocidente travava um "combate" ideológico (DAVIES, 2002, p. 39).

Ainda que em teoria seja possível estabelecer definições simples sobre o que seria uma pessoa refugiada, na prática a tarefa é mais laboriosa. A delimitação do rótulo legal nos termos do Direito Internacional diz respeito a uma pessoa que foi reconhecida ou por um governo nacional ou pelo ACNUR como alguém que necessita de proteção internacional sob os termos da Convenção 1951 e seu subsequente Protocolo de 1967. Não obstante, essas definições retangulares são desafiadas pelas tendências migratórias globais da atualidade. Pode, de fato, o refúgio ser separado de outros fenômenos migratórios? Ainda, são as refugiadas diferentes de outras migrantes?

Esta divisão no mundo prático é difícil de ser feita, se não impossível. As razões pelas quais uma pessoa foge de seu país de origem são múltiplas e frequentemente abarcam diversos fatores combinados que, por fim, forçam-na a 
deixar seu lar. As causas econômicas e políticas da migração não são mutuamente excludentes, mas parte de um contínuo.

Dessa forma, autoras como Jane Freedman (2007) e Elena Fiddian-Qasmiyeh (2014) discorrem sobre a impossibilidade de se classificar as migrações como resultado de circunstâncias políticas ou econômicas, ou como "forçadas" ou "voluntárias". É questionável a própria existência de uma migração verdadeiramente "voluntária", salvos raros casos (FREEDMAN, 2007, p. 4). O que parece acontecer na realidade dos deslocamentos é uma continuidade de situações que variam da voluntariedade à coação em migrar (BINDER; TOSIC, 2005).

A distinção entre migrantes forçadas(os) e voluntárias(os) por vezes é feita de uma forma que não é neutra, classificando os dois grupos de migrantes dentro de um esquema político onde a pessoa em situação de refúgio é retratada como uma "boa" migrante, uma vítima indefesa de opressões. Em contrapartida, os indivíduos que migram em busca de melhores condições de vida são frequentemente representados nas mídias e nas políticas como migrantes "maus", fraudes que buscam adentrar outro país a fim de desfrutar dos benefícios das condições econômicas desenvolvidas e aproveitar do estado de bem-estar social nos Estados ocidentais (FREEDMAN, 2007, p. 4).

O termo "migração forçada" também reincide ao problema da categorização, ou o que Stephen Scheel e Vicki Squire (2014) chamam de "figuras de migração", na qual a imagem da(o) migrante forçada(o) será solidificada em contraste a(o) migrante "irregular". As figuras de migração são lentes analíticas úteis para identificar como o status legal do refúgio é distribuído e institucionalizado com o intuito de distinguir as pessoas refugiadas de outras categorias de migrantes (ZETTER, 2007). Ademais, a utilização desta metodologia facilita o entendimento das maneiras como as(os) migrantes em geral têm sido problematizadas(os), marginalizadas(o)s e até mesmo criminalizadas(os), tanto as "forçadas(os)", as "irregulares" (SCHEEL; SQUIRE, 2014, p. 9) ou as "voluntárias(os)/econômicas(os)".

A distinção entre migrante "forçada(o)" (político) e "voluntária(o)" (econômico) consagrada pela Convenção de 1951 é, portanto, concebida como uma construção artificial e denotada de implicações legais e políticas significativas. A definição da(o) refugiada(o) criada pela Convenção é considerada estreita, além de ativamente excluir diversas pessoas, obrigadas a se deslocar, de usufruírem de sua proteção (CASTLES, 
2003; ZETTER, 2007; SCHEEL; SQUIRE, 2014). Por exemplo, foi apenas nos anos 2000 que o ACNUR passou a reconhecer a violência sexual e outras perseguições de gênero como razão legítima para a busca do refúgio (BARTOLOMEI; PITTAWAY, 2001).

Assim como grande parte do pensamento Ocidental, a definição da(o) refugiada(o) no enquadramento da Convenção de Genebra é baseada em categorias hierárquicas de inclusão e exclusão (VALJI, 2001). A própria hierarquização das categorias migratórias "voluntárias" e "forçadas" tem impactos distintos sobre as mulheres, justamente porque os efeitos estruturais das esferas políticas e econômicas afetam-nas desproporcionalmente. Por exemplo, Nahla Valji (2001) mostra como a vulnerabilidade econômica frequentemente imposta às mulheres de todo mundo prejudicam-nas em outros espaços, e a distinção binária entre direitos políticos e direitos econômicos cria uma hierarquia de práticas persecutórias.

Diante desse contexto geral da construção categórica excludente de quem é (e quem não pode ser) uma pessoa refugiada, as próximas subseções apresentarão os impactos das desigualdades de gênero e de raça na experiência migratória de mulheres.

\section{PAPO DE MULHER: SITUANDO AS MULHERES REFUGIADAS NO DEBATE GLOBAL DO REFÚGIO}

Entre o patriarcado e o imperialismo, a constituição do sujeito e formação do objeto, a figura da mulher desaparece [...]. Não há espaço para que a subalterna possa falar.

(SPIVAK, 1988, p. 306-307)

Rosana Baeninger e Roberta Peres (2017) salientam a importância de incorporar as diferenças entre homens e mulheres no processo migratório a partir de uma perspectiva analítica de gênero, pois o deslocamento é estruturado por diferenças socialmente construídas ao longo da migração. Com base nessas diferenças, a experiência da mulher será estruturada pelos regimes políticos e legislativos de seu país de origem, do país em trânsito e do país onde finalmente requererá o refúgio.

A estratificação, por conseguinte, ocorre em todos os estágios do processo migratório, sendo causada tanto pelo processo de globalização quanto pelos 
contextos locais e nacionais. Ainda, como argumentado por Monica Boyd e Elizabeth Grieco (2003, p. 61), as relações de gênero estão arraigadas nos deslocamentos e seus impactos na vida das refugiadas, sendo necessário observar a forma como "fatores sutis e óbvios se misturam para criar diferentes experiências ao longo da migração".

O gênero é um conceito desenvolvido a fim de contestar a naturalização das diferenças sexuais em diversas arenas da vida social e política entre homens e mulheres. Assim, as teorias e práticas feministas buscam explicar e mudar sistemas históricos de diferença sexual, nos quais "homens" e "mulheres" são socialmente constituídos e posicionados em relações de hierarquias e antagonismos (NFAHABBENYI, 2005, p. 259).

Em termos de políticas de refúgio, as desigualdades de gênero podem afetar os homens de maneiras específicas: se as construções de gênero representam as mulheres refugiadas como mais "vulneráveis", então os homens (e particularmente os homens jovens) podem ser construídos como mais "ameaçadores" e, assim, podem receber uma atenção especial (FREEDMAN, 2007, p. 17). De fato, como assinala $R$. C. Carpenter (2006), a construção de mulheres como vulneráveis pode significar que os programas de proteção serão direcionados especificamente a elas, e a vulnerabilidade e insegurança dos homens tornam-se invisíveis.

Por outro lado, Linda Bartolomei e Eileen Pittaway (2001) demonstram como as proteções legais para mulheres ao redor do globo, inclusive para refugiadas que experienciaram violência, são em sua maioria cegas quanto às questões de gênero e não abordam a realidade das vidas das mulheres. Dessa forma, as refugiadas podem ser discriminadas em situações de conflito armado, bem como nas determinações do refúgio e no processo de reassentamento (BARTOLOMEI; PITTAWAY, 2001).

Portanto, uma análise de gênero funciona como uma lente pela qual a política mundial pode ser examinada a fim de "ver como o mundo é moldado por conceitos, práticas e instituições enviesadas quanto ao gênero" (PETERSON; RUNYAN, 1993, p. 1). Utiliza-se, então, a lente de gênero no presente artigo no intuito de "ver" e entender o modo como as estruturas de gênero e as relações de poder afetam as experiências de mulheres refugiadas, e como as políticas nacionais e internacionais para o refúgio auxiliam na construção e reforço destas relações. 
Aplicando a lente de gênero percebemos que historicamente o Regime Internacional de Refúgio tem excluído as mulheres do direito à proteção por razões de perseguição. Com o exposto na seção anterior, o Regime foi pensado segundo a experiência europeia do pós-Segunda Guerra, além de partir de uma visão androcêntrica. Isso significa que toda a estrutura de refúgio foi elaborada por "homens que ocupavam cargos de poder nas burocracias estatais e dentro de Organismos Internacionais" (MATOS, 2018, p. 62).

Tanto é verdade que as necessidades diversificadas das mulheres em situação de refúgio não foram reconhecidas dentro do sistema do ACNUR exceto em anos relativamente recentes (BARTOLOMEI; PITTAWAY, 2001). Apenas em 1985 as experiências das mulheres foram incluídas como itens da agenda na reunião anual do Comitê Executivo do ACNUR. Nesta reunião, a Conclusão XLIV considerou o vínculo entre a natureza generalizada da violência sexual perpetrada contra mulheres refugiadas e seu deslocamento (BARTOLOMEI; PITTAWAY, 2001).

Esse cenário é refletido pela escassez, nos estudos migratórios em geral, de análises de gênero por parte dos cientistas políticos (DONATO, 2006). Na área das Relações Internacionais essa carência é ainda mais aguda: quando analisadas as principais bases de dados brasileiras de teses e dissertações, como a CAPES e a Biblioteca Digital Brasileira de Teses e Dissertações, poucas são encontradas pesquisas acerca da interseccionalidade do gênero e da migração forçada no domínio das RI. Nos principais periódicos brasileiros da citada área do conhecimento, o número de artigos acerca da temática também é baixo.

A pesquisa de gênero nas Relações Internacionais como um todo permite que analisemos como as relações construídas entre homens e mulheres têm impactos diferentes na estruturação de suas experiências. Deste modo, a análise de gênero das questões de refúgio demonstra que, além da constatação de que mulheres migram de seus países de origem por razões distintas dos homens, a forma como ela será acolhida nas sociedades dependerá também do ordenamento dos papéis de gênero no país receptor.

Os estudos de gênero no âmbito das migrações forçadas fazem parte de um movimento que por muito tempo esteve silenciado, no qual a figura do migrante era assumida como masculina, ao passo que as mulheres migrantes foram excluídas da maioria das pesquisas na área (FREEDMAN, 2007). Uma das primeiras mudanças 
nessa invisibilidade das mulheres e do gênero nos estudos migratórios foi a constatação de que, na realidade, as mulheres sempre migraram e que na contemporaneidade cada vez mais mulheres estão migrando (FREEDMAN, 2007).

Ademais, Freedman (2007) ressalta a importância de se observar que as experiências das mulheres são influenciadas não apenas por sua posição social como mulher, mas também pela sua classe, raça ou etnia, além de sua idade e orientação sexual. Estes e outros marcadores irão impactar as causas e os meios utilizados pelas mulheres para migrar, além de como será sua experiência quando chegar em um novo país (FREEDMAN, 2007). Além disso, as experiências das mulheres serão estruturadas por regimes políticos e legislativos de seu país de origem, do país em trânsito, e do país onde finalmente solicitarão o refúgio.

No âmbito geral da ONU, ocorreram diversas discussões acerca da inclusão da igualdade de gênero na Carta da Organização: um dos principais argumentos contra tal medida girava em torno da noção de universalidade, sob o argumento de que o termo "homens" incluía ambos os gêneros (SKARD, 2008, p. 47). Nas reuniões da formulação da Convenção de 1951, qualquer inclusão de questões de gênero na definição do que era um refugiado foram dispensadas sob a base de que "a igualdade dos sexos seria uma questão para legislações nacionais" (EDWARDS, 2010, p. 23). Inclusive, os decisores políticos eram céticos quanto à existência de perseguições com base em questões de gênero. Não é de se surpreender que, conforme Alice Edwards (2010), nenhuma mulher participou das discussões diplomáticas em Genebra.

Diante das críticas expostas sobre da invisibilidade das mulheres, particularmente das mulheres do Sul Global no que tange o RIR, o ACNUR reconheceu que:

Historicamente, a definição do que é um refugiado tem sido interpretada através de uma estrutura de experiências masculinas, o que significa que diversas reivindicações de mulheres e homossexuais não são reconhecidas. (ACNUR, 2002, p. 1)

Nesse sentido, a resposta do órgão e dos principais decisores da política internacional não foi a inclusão das perseguições de gênero como razão legítima para a solicitação de refúgio, mas sim a formulação de recomendações que poderiam ser aplicadas a partir de interpretações sensíveis ao gênero (FIDDIAN-QASMIYEH, 2014). Isso levou ao desenvolvimento de diversas diretrizes internacionais para lidar 
com as necessidades específicas de refugiadas, como as "Diretrizes para a Proteção de Mulheres Refugiadas" (ACNUR, 1991) e o "Manual para a Proteção de Mulheres e Garotas" (ACNUR, 2008).

O primeiro grande problema com a falta da institucionalização das perseguições de gênero no âmbito da Convenção é o fato de que cada país pode interpretá-la conforme seus interesses particulares, e as diretrizes, como o próprio nome sugere, tornam-se apenas sugestões sobre como lidar com a questão.

Outra questão importante a ser salientada é que, como apontado por FiddanQasmiyeh (2014, p. 400), apesar de destacar as limitações das interpretações da Convenção de 1951, essas diretrizes reproduzem uma visão predominante de que "mulheres e meninas refugiadas têm necessidades especiais de proteção que refletem seu gênero" e "esforços especiais podem ser necessários para resolver problemas enfrentados especificamente por mulheres refugiadas". Isso sugere que o caráter neutro de gênero do Regime foi desenvolvido tendo em mente um refugiado homem, branco e heterossexual. Fiddan-Qasmiyeh (2014) então nos questiona se endereçar as necessidades de refugiadas mulheres (e mulheres/homens LGBTI) via diretrizes "excepcionais" abordaria adequadamente os vieses conceituais e lacunas de proteção na avaliação das causas da migração forçada (FIDDIAN-QASMIYEH, 2014, p. 400).

Em suma, os esforços em aprimorar as diretrizes e expandir o escopo de proteção do Regime a fim de abarcar as perseguições com base no gênero criaram uma identidade basilar das pessoas refugiadas a partir de um standpoint eurocentrado e androcêntrico, sendo as mulheres retratadas como vítimas monolíticas, passivas, dependentes e vulneráveis, perpetuando sua periferização e desprovendo-as de agência na arena da política internacional. Por consequência, como argumentado por Fiddan-Qasmiyeh (2014, p. 400), as mulheres e "outros grupos sociais" são identificadas como fugindo de formas de perseguição "diferentes, extraordinárias e não-convencionais", requerendo "esforços especiais" de proteção.

\section{A INTERSECCIONALIDADE NA QUESTÃO MIGRATÓRIA: ONDE A ALTERIDADE, A RAÇA E O GÊNERO SE ENCONTRAM}

Ao analisar as estruturas que irão influenciar a experiência do deslocamento forçado, é preciso considerar que, além das construções de gênero, as mulheres refugiadas são frequentemente categorizadas de acordo com a sua raça, sua etnia, 
sua nacionalidade e sua classe social. Na literatura, esses múltiplos marcadores dão nome a uma abordagem chamada interseccionalidade, que busca desmantelar definições hegemônicas de neutralidade, objetividade, racionalidade e universalidade na ciência. Essas definições são criadas a partir da visão de mundo de indivíduos que criaram essa ciência: homens, brancos, ocidentais, membros de classes dominantes (HIRATA, 2017; LOWY, 2009). A interseccionalidade diz respeito a:

uma teoria transdisciplinar que visa apreender a complexidade das identidades e das desigualdades sociais por intermédio de um enfoque integrado. Ela refuta o enclausuramento e a hierarquização dos grandes eixos da diferenciação social que são as categorias de sexo/gênero, classe, raça, etnicidade, idade, deficiência e orientação sexual. $O$ enfoque interseccional vai além do simples reconhecimento da multiplicidade dos sistemas de opressão que opera a partir dessas categorias e postula sua interação na produção e na reprodução das desigualdades sociais.

(BILGE, 2009, p. 70)

O conceito de interseccionalidade surgiu dentro do movimento feminista negro e da teoria racial crítica como uma ferramenta política e analítica que problematizou abordagens que objetificavam as experiências dos indivíduos de forma monolítica (CRENSHAW, 1989). Dessa forma, as análises interseccionais situavam o conhecimento dentro de uma rede complexa de relações de poder, incluindo dimensões raciais, étnicas, de classe, de gênero e de orientação sexual (CRENSHAW, 1989; COLLINS, 2000).

Conforme Maria Lugones (2014), o sistema capitalista moderno organiza o mundo de acordo com categorias homogêneas, atômicas e separáveis. Assim, a intersecção entre raça, classe, sexualidade e gênero é desconsiderada, e as mulheres negras e do terceiro mundo tornam-se invisíveis nessa lógica dicotômica e hierárquica (LUGONES, 2014). Diante desse arranjo hegemônico, as mulheres refugiadas encontram-se marginalizadas e como subalternas têm suas vozes silenciadas.

Através das ferramentas da interseccionalidade e pensando no contexto das migrações forçadas, é possível observar como hostilidades, violências e várias formas de controle ou exclusão podem ser experimentadas não apenas dentro da família e da comunidade, como também durante o deslocamento e por membros da sociedade anfitriã. A importância de uma análise da interseccionalidade nas migrações se dá porque as experiências das mulheres são influenciadas não apenas por sua posição social como mulher, mas também no âmbito de sua classe, raça ou etnia, além de sua idade e orientação sexual. Estes e outros fatores irão impactar as causas e os meios 
utilizados pelas mulheres para migrar, além de como será sua experiência quando chegar a um novo país.

Experiências de racismo são obviamente variáveis e dependentes do contexto. No entanto, Freedman (2007) argumenta que nas sociedades em que os apontamentos xenófobos da questão do refúgio prevaleceram no debate público, é provável que haja um aumento nas reações racistas, de modo que mesmo que tenham residência legal, os direitos de cidadania dos refugiados podem ser minados por estas relações de racismo social e xenofobia.

No Brasil, a população migrante negra é a mais afetada nos processos de exclusão social e violação dos direitos humanos, sendo que os casos de racismo e xenofobia fazem com que ela seja hiper-vulnerabilizada e excluída da vida social brasileira (SILVA et al., 2018). Ademais, as maneiras pelas quais o racismo é expresso possuem um viés de gênero e, portanto, irão afetar diferentemente as mulheres refugiadas negras. Sendo assim, essas construções enfatizam não apenas as diferenças entre homens e mulheres, como também entre as nacionais e as "outras" mulheres.

Além do racismo, quando se situa a refugiada em uma classe social definida (a de "refugiada"), a mulher enfrenta desafios particulares em relação às políticas migratórias dos países receptores. Um fator chave na integração das refugiadas na sociedade hospedeira é o acesso ao mercado de trabalho. É notável que a maioria das refugiadas têm dificuldades em encontrar emprego nos países acolhedores e em ter devidamente reconhecidas suas qualificações obtidas no país de origem (SILVA et al., 2018).

No Brasil, a dificuldade em validar diplomas, a demorada burocracia para a aquisição do status de refugiada e a escassez de iniciativas públicas para a integração desses indivíduos na sociedade podem trabalhar para intensificar ainda mais a exclusão. Como apontado por Karine Silva et al. (2018), ocorre um subaproveitamento da força de trabalho das pessoas negras e migrantes no país, que não são absorvidos pelo mercado de trabalho devido às dificuldades burocráticas em ter suas habilidades validadas e ao racismo estrutural que afeta a população negra, seja ela brasileira ou estrangeira.

Essas barreiras no acesso ao mercado de trabalho podem ser vividas de maneira diferente por mulheres e homens, tanto por conta das relações de gênero 
desiguais em seus países de origem quanto devido às relações e estruturas de gênero na sociedade de acolhimento. Assim, muitas mulheres podem ter menos acesso à educação e qualificações do que os homens e podem ter tido menos experiência de trabalho em seus países de origem. As refugiadas podem também ter dificuldade em adentrar o mercado de trabalho devido à falta de provisão para cuidados infantis, e o fato de ficarem em casa com os filhos pode, por sua vez, aumentar seu isolamento social e tornar ainda mais difícil a busca por um emprego.

Nesse sentido, Silva et. al (2018) aponta que, assim como os negros brasileiros, os migrantes africanos e afrodescendentes são vítimas de um processo de exclusão social e violação de direitos humanos básicos. Devido a sua condição racial, atrelada à xenofobia, os migrantes negros recaem "numa condição de hipervulnerabilidade, o que prejudica fortemente a integração desses povos na vida social e no mercado de trabalho" (SILVA ET. AL, 2018, p. 288). Percebe-se, assim, que uma tripla opressão será imposta sobre as mulheres negras que se refugiam: por ser mulher, por ser negra e por ser refugiada.

\section{CONSIDERAÇÕES FINAIS}

A partir do exposto no artigo, conclui-se que as mulheres refugiadas são excluídas do Sistema Internacional, visto que este é alicerçado nos preceitos de território nacional e cidadania, além de ser estruturado por uma hierarquia racial, cultural e de gênero que desprivilegia aquelas pessoas que migram do Sul Global, em especial as mulheres negras. São excluídas também das histórias de pertencimento às comunidades políticas que gozam de direitos e deveres perante estes Estados. Em contrapartida, estas histórias de pertencimento - ou a falta delas - são utilizadas para justificar a contínua exclusão destas migrantes, seja na entrada ou no usufruto dos aparatos sociais nos países acolhedores.

É possível argumentar que a marginalização das refugiadas no cenário internacional repete-se não somente na maioria dos Estados ocidentais, mas também em alguns países do Sul Global, como o Brasil. Especialmente devido ao estabelecimento da cidadania como modo correto de pertencimento nas sociedades nacionais, à dominação colonial que arquitetou e institucionalizou o mundo em uma hierarquia étnico-racial e à colonialidade do refúgio, que utiliza mecanismos do Direito 
Internacional em favor de interesses estatais específicos, intensifica-se o racismo cultural contra migrantes não-ocidentais.

As mulheres refugiadas, nesse contexto, enfrentam um conjunto de desafios - desde as razões que a fizeram fugir de seu país de origem, suas experiências durante o processo migratório, até, por fim, o estabelecimento no país acolhedor. A lente de gênero, o pós-colonialismo, a decolonialidade e os estudos intersecionais na temática do refúgio - e nas Relações Internacionais como um todo - permitem que analisemos e desconstruímos a exclusão cultural, social, política e econômica de mulheres refugiadas em tempos de intensos deslocamentos globais.

\section{REFERÊNCIAS}

ADAMSON, Fiona B. Crossing Borders: International Migration and National Security. International Security, v. 31, n. 1, 2006, pp: 163-199.

ACNUR. Manual para a Proteção de Mulheres e Garotas. 2002. Disponível em: $<$ https://www.refworld.org/cgibin/texis/vtx/rwmain/opendocpdf.pdf?reldoc=y\&docid=5 21c53c94> Acesso em: agosto de 2018.

ACNUR. Global Trends: Forced Displacement in 2017. 2018. Disponível em: <http://www.unhcr.org/5b27be547> Acesso em: 25 de junho de 2018.

ACNUR. Mid-Year Trends 2018. 2019. Disponível em: <https://www.unhcr.org/statistics/unhcrstats/5c52ea084/mid-yeartrends-2018.html> Acesso em: 12 de fevereiro de 2019.

BAENINGER, Rosana; PERES, Roberta. Migração de crise: a migração haitiana para o Brasil. Revista Brasileira de Estudos Populacionais v.34, n.1, 2017, pp.119-143.

BARTOLOMEI, Linda; PITTAWAY, Eileen. Refugees, Race and Gender: The Multiple Discrimination against Refugee Women. Canada's Journal on Refugees, v. 19, n. 6, 2001, p. 21-32

BETTS, Alexander. International Relations and Forced Migration. In: FIDDIANQASMIYEH, Elena et al. The Oxford Handbook of Refugee and Forced Migration Studies. Oxford: Oxford University Press, 2014.

BILGE, Sirma. Théorisations féministes de l'intersectionnalité. Diogène, v. 225, n. 1, 2009, pp. 70-88.

BINDER, S. TOSIC, J. Refugees as a Particular Form of Transnational Migrations and Social Transformations: Socioanthropological and Gender Aspects. Current Sociology, v. 53, n. 4, 2005, pp. 607-624. 
BULL, Hedley. A Sociedade Anárquica: um estudo da ordem na política mundial. Brasília \& São Paulo: IPRI, UNB, Imprensa Oficial, 2001. 390 p.

BOYD, Monica; GRIECO, Elizabeth. Women and Migration: Incorporating Gender into International Migration Theory. 2003. Disponível em: $<$ https://www.migrationpolicy.org/article/women-and-migration-incorporating-genderinternational-migration-theory> Acesso em: 20 de julho de 2018.

CASTLES, Stephen. The International Politics of Forced Migration, Development, v. 46, n. 3, 2003, pp. 11-20.

CASTLES, Stephen. LOUGHNA, Sean. Trends in Asylum Migration to Industrialized Countries, 1990-2001. In: BORJAS, Georges. Poverty, International Migration and Asylum. Basingstoke: Palgrave Macmillan, 2005.

CASTRO-GÓMEZ, Santiago; GROSFOGUEL, Rámon. El Giro Decolonial: Reflexiones para una diversidad epistémica más allá del capitalismo global. Bogotá: Siglo del Hombre, 2005.

CHIMNI, B. S. The Geopolitics of Refugee Studies: A view from the South. Journal of Refugee Studies, v. 11, n. 4, 1998. pp: 350-374.

CHOWDBRY, Geeta; NAIR, Sheila. Power, Postcolonialism and International Relations. London and New York: Routledge, 2002.

COLLINS, Patricia. Black feminist thought: knowledge, consciousness, and the politics of empowerment. London: Routledge, 2000.

CONVENÇÃO RELATIVA AO ESTATUTO DOS REFUGIADOS. 1951. Disponível em: $<$ https://www.acnur.org/fileadmin/Documentos/portugues/BDL/Convencao relativa a o Estatuto dos Refugiados.pdf?view=1> Acesso em: junho de 2018.

CRENSHAW, Kimberle. Demarginalizing the Intersection of Race and Sex: A Black Feminist Critique of Antidiscrimination Doctrine, Feminist Theory and Antiracist Politics. University of Chicago Legal Forum, n.1, 1989, pp. 139-167.

DAVIES, Sara. 'Truly' International Refugee Law/ Or Yet Another East/West Divide? Social Alternatives, v. 21, n. 4, 2002, pp. 37-43.

DONATO, Katharina et al. A Glass Half-Full? Gender in Migration Studies. International Migration Review, v. 40, n. 1, 2006, pp. 3-26.

DOTY, Roxanne. Imperial Encounters: The Politics of Representation in North-South Relations. Minnesota: Univ of Minnesot Press, 1996. 232 p.

EDWARDS, Alice. Transitioning Gender: Feminist engagement with international refugee law and policy. Refugee Survey Quarterly, v. 29, n. 2, 2010, pp. 21-46. 
FANON, Frantz. Os Condenados Da Terra. Juiz de Fora: UFJF, 2006.

FIDDIAN-QASMIYEH, Elena. Gender and Forced Migration. In: FIDDIAN-QASMIYEH, Elena et al. The Oxford Handbook of Refugee and Forced Migration Studies. Oxford: Oxford University Press, 2014.

FREEDMAN, Jane. Gendering the International Refugee Debate. Nova York: Palgrave Macmillan, 2007.

GROVOGUI, Siba. Postcolonialism. In: DUNNE, Tim; KURKI, Milja; SMITH, Steve. International Relations Theories: Discipline and Diversity. Oxford: Oxford University Press, 2013.

GROSFOGUEL, Ramón. Para decolonizar os estudos de economia política e os estudos pós-coloniais: Transmodernidade, pensamento de fronteira e colonialidade global. Revista Crítica de Ciências Sociais, v. 80., 2008, pp. 115-147.

. Las migraciones coloniales del Caribe a Estados Unidos y Europa Ocidental: Colonialidades diferenciadas en cuatro centros del sistema-mundo. Revista de análisis cultural, v. 9, 2017, pp. 225-250.

HADDAD, Emma. The refugee in international society: between sovereigns. Cambridge: Cambridge University Press, 2008. 254 p.

HUFFPOST BRASIL. Chegada de refugiados faz xenofobia crescer mais de $600 \%$ no Brasil, mas nem 1\% dos casos chega à Justiça. 2016. Disponível em: $<$ https://www.huffpostbrasil.com/2016/06/20/chegada-de-refugiados-faz-xenofobiacrescer-mais-de-600-no-bras a 21688171/> Acesso em: 20 de junho de 2018.

HUYSMANS, Jef. The European Union and the Securitization of Migration. Journal of Common Market Studies, v. 38, n. 5, 2000, pp: 751-777.

KRATOCHWIL, Friedrich. RUGGIE, John. International Organization: A State of the Art on an Art of the State. International Organization, v. 40, n. 4, 1986, pp. 753-775.

LUGONES, María. Colonialidad y Género. Tabula Rasa, n.9, 2008, pp. 73-101.

MALKKI, Liisa. Refugees and Exile: From "Refugee Studies" to the National Order of Things. Annual Review of Anthropology, v. 24, 1995, pp. 495-523.

MATOS, Ana Carolina. O sistema de proteção a refugiados e sua atuação perante as refugiadas sírias no Brasil. Dissertação (Mestrado em Estudos Comparados Sobre as Américas) - Departamento de Estudos Latino-Americanos, Universidade de Brasília, Brasília, 2018. $129 \mathrm{p}$

PERSAUD, Randoplh. Situating Race in International Relations: The dialectics of civilizational security in American immigration. In: CHOWDBRY, Geeta; NAIR, Sheila. Power, Postcolonialism and International Relations. London and New York: Routledge, 2002. 
PETERSON, V. Spike; RUNYAN, Anne Sisson. Global Gender Issues. Westview Press, 1993.

QUIJANO, Anibal. Coloniality of Power, Eurocentrism and Latin America. Views from South, v. 1, n. 3, 2000, pp. 533-580.

SAID, Edward. Orientalismo: o Oriente como invenção do Ocidente. São Paulo: Companhia das Letras, 1990.

SCALETTARIS, Giullia. Refugee studies and the international refugee regime: a reflection on desirable separation. Refugee Survey Quarterly, v. 26, n. 3, 2007, pp. 3650.

SCHEEL, Stephan. SQUIRE, Vicki. Forced Migrants as 'Illegal' Migrants. In: FIDDIANQASMIYEH, Elena et al. The Oxford Handbook of Refugee and Forced Migration Studies. Oxford: Oxford University Press, 2014.

SILVA, Karine et al. Santa Catarina no roteiro das diásporas: os novos imigrantes africanos em Florianópolis. Rev. Katálysis. v.21, n.2, 2018, pp. 281-292.

SKARD, T. Getting our history right: How were the equal rights of women and men included in the Charter of the United Nations? Forum for Development Studies, v. 1, 2008, pp. 37-60.

SPIVAK, Gayatri. Pode o Subalterno Falar? Belo Horizonte: Editora UFMG, 2010.

VALJI, Nahla. Women and the 1951 Refugee Convention: Fifty Years of Seeking Visibility. Canada's Journal on Refugees, v. 19, n. 5, 2001, p. 25-36.

WALLERSTEIN, Immanuel. The Capitalist World-Economy. Cambridge: Cambridge University Press, 1979.

WALTZ, Kenneth. Theory of International Politics. Illinois: Waveland Press, 1979.

ZETTER, Roger. More Labels, Fewer Refugees: Remaking the Refugee Label in an Era of Globalization. Journal of Refugee Studies, v. 20, n. 2, 2007, pp. 172-192.

Recebido em: 30/08/2018

Aprovado em: 26/12/2018 